\title{
Using Clinical Databases to Verify the Impact of Regulatory Agency Alerts in Japan: Hepatitis B Testing Behavior After an Alert Regarding Risk of Viral Reactivation
}

\author{
Yukio Udagawa $^{1} \cdot$ Shinya $_{\text {Ohno }}{ }^{2} \cdot$ Shintaro Nakagawa $^{3} \cdot$ Kazutaka Sugimoto $^{1} \cdot$ \\ Joji Mochizuki ${ }^{1}$
}

Published online: 13 August 2015

(c) The Author(s) 2015. This article is published with open access at Springerlink.com

\begin{abstract}
Background Measures of the effectiveness of risk minimization activities are necessary for the appropriate use of drugs, and clinical databases are a low-cost method of quickly producing such results.

Objective The aim of this study was to explore the secondary application of clinical databases in verifying the impact of risk minimization activities; specifically, whether such databases could be used to identify changes in hepatitis B virus testing behavior after an alert from the Pharmaceuticals and Medical Devices Agency (PMDA) in Japan.

Methods Patient data from December 1, 2010 to November 30, 2012 were extracted from the Medical Data Vision clinical database. The percentages of patients tested for hepatitis B virus DNA (HBV-DNA), hepatitis B surface antigen (HBsAg), and hepatitis B surface antibody ( $\mathrm{HBsAb}) /$ hepatitis B core antibody ( $\mathrm{HBcAb}$ ) were compared 1 year before (consecutive 6-month periods $A$ and $B$ ) and 1 year after (consecutive 6-month periods $\mathrm{C}$ and $\mathrm{D}$ ) a PMDA alert regarding viral reactivation in patients receiving immunosuppressive agents.

Results Data for 9866 patients in the clinical database were analyzed. After the PMDA alert, the percentage of patients tested for HBV-DNA linearly increased in periods
\end{abstract}

Yukio Udagawa

udagawayko@chugai-pharm.co.jp

1 Drug Safety Division, Chugai Pharmaceutical Co., Ltd., 1-1 Nihonbashi-Muromachi 2-Chome, Chuo-ku, Tokyo, Japan

2 Project and Lifecycle Management Unit, Chugai Pharmaceutical Co., Ltd, Tokyo, Japan

3 Clinical Development Division, Chugai Pharmaceutical Co., Ltd, Tokyo, Japan
A to D: $4.70 \%(n=262 / 5571), 5.78 \%(n=330 / 5710)$, $6.52 \% \quad(n=398 / 6101)$, and $7.59 \% \quad(n=479 / 6315)$. However, no changes were observed in the rates of HBsAg and $\mathrm{HBcAb} / \mathrm{HBsAb}$ testing (around 50 and $70 \%$, respectively). Overall testing rates appeared to differ depending on disease and drug type.

Conclusion These findings suggest that the PMDA alert was effective at recommending HBV-DNA testing. This secondary application of clinical databases may be effective for verifying the impact of risk minimization activities.

\section{Key Points}

We used a clinical database to investigate the relationship between a PMDA alert and changes in monitoring behavior for hepatitis B infection in patients receiving immunosuppressive agents. We also investigated this relationship in subgroups stratified by type of disease or immunosuppressive drug.

Results indicated that a clinical database could be used to quantitatively verify the impact of risk minimization activities like this alert, which could support implementation of future risk minimization activities and verification of their impact.

Although the use of clinical databases to measure the effectiveness of risk minimization activities in pharmacovigilance is necessary for the appropriate use of drugs, the use of clinical databases is not yet common in Japan. We expect this study to encourage similar research in the future. 


\section{Introduction}

As more clinical databases become available for general use, researchers are exploring a variety of potential new applications. Recent studies have used clinical databases to verify the impact of drug risk minimization activities [1-3]. Several such studies have investigated the effects on hepatitis B screening in cancer patients undergoing chemotherapy. Hanson et al. comparatively investigated the percentage of cancer patients tested for hepatitis B surface antigen (HBsAg) and hepatitis B core antibody $(\mathrm{HBcAb})$ at the onset of chemotherapy in the US before and after the publication of clinical care guidelines [1]. Hwang et al. similarly reported the changes over time in the percentage of cancer patients tested for HBsAg and $\mathrm{HBcAb}$ when starting chemotherapy in the US [2]. In Japan, Ikeda et al. used an administrative health insurance claims database to compare the implementation of hepatitis B screening tests before and after the publication of Japanese hepatitis B virus (HBV) guidelines in cancer patients receiving chemotherapy for the first time [3].

Measures of the effectiveness of risk minimization activities are necessary for the appropriate use of drugs [4]. Using clinical databases for this purpose is a relatively lowcost method and provides rapid results. The drug safety departments of pharmaceutical companies are most often responsible for verifying the impact of drug risk minimization activities; however, thorough verification is rare, with communication usually limited to a one-way flow of information to the medical community. After developing the capacity to utilize clinical databases, researchers at Chugai Pharmaceutical Co., Ltd (Chugai) investigated their utility in databases verifying the impact of risk minimization activities.

In October 2011, Japan's Pharmaceuticals and Medical Devices Agency (PMDA) issued an alert regarding the risk of hepatitis $\mathrm{B}$ reactivation with immunosuppressive agents [5]. However, no studies to date have used a clinical database to investigate the relationship between the PMDA alert and changes in hepatitis B testing behavior for patients receiving immunosuppressive agents.

The PMDA alert recommended that "when administering drugs with immunosuppressive effects, healthcare professionals should carefully observe patients' signs and symptoms related to hepatitis B virus growth by monitoring results of liver function tests or hepatitis virus markers". This alert was a suitable target to examine the potential for using clinical databases to verify the impact of distributing information to the medical community. Doctors aware of the alert when prescribing immunosuppressive agents would presumably then perform regular screening (such as HBsAg testing) and monitoring (such as HBV-DNA testing) according to Japanese HBV guidelines $[6,7]$. The percentage of patients tested for HBsAg or monitored for HBV-DNA would be expected to increase. These changes in testing status would be reflected in databases such as the Medical Data Vision (MDV) clinical database, which includes the results of HBsAg testing in Japan.

This study aimed to clarify whether a pharmaceutical company can use a clinical database to quantitatively verify the impact of risk minimization activities such as health authority alerts, which could support future implementation of risk minimization activities and verification of their impact.

\section{Methods}

\subsection{Study Design}

This cohort study used the MDV clinical database to investigate patients prescribed immunosuppressive agents. To identify changes in testing behavior, the status of patient testing for $\mathrm{HBV}$ markers was investigated during two consecutive 6-month periods before (A and $\mathrm{B}$ ) and after (C and D) the PMDA alert (Fig. 1).

This study was conducted using a hospital claims database stored in hospital electronic information systems

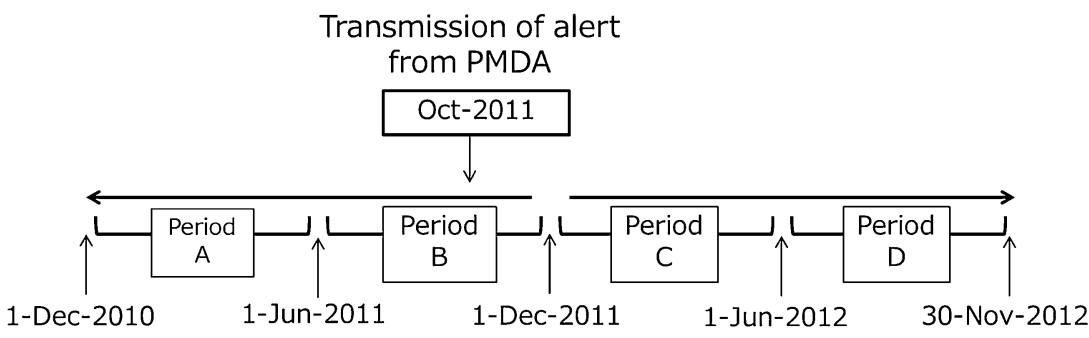

Fig. 1 Four observation periods before and after a Pharmaceuticals and Medical Devices Agency (PMDA) alert. This study investigated whether any change could be confirmed in laboratory testing for hepatitis B in patients treated with immunosuppressive agents before and after an alert from the PMDA 
constructed by Medical Data Vision Co., Ltd (MDV; Tokyo, Japan). The MDV database covers approximately 8.14 million patients in 153 hospitals across Japan, with bed numbers ranging from 20 to more than 1000, and including about $10 \%$ of all acute phase hospitals, except university hospitals. The database uses a diagnostic procedure combination payment system/per-diem payment system and comprises anonymized patient identifiers attached to data on sex, birth year, department visited, date of medical service, diagnosis codes, hospitalization status, medical procedures, test orders, operations, and prescriptions [8].

During the study, the authors did not access any patient data in the MDV clinical database. MDV performed and supplied the results of aggregate analysis based on the analysis items and methods in the study protocol.

\subsection{Subjects}

Patients in the MDV clinical database who were already receiving (AR) or newly receiving (NR) an immunosuppressive agent (Table 3 in "Appendix") during any of the periods A through D (defined below) were investigated. Although steroids and the antirheumatic drug methotrexate are listed in the PMDA alert [5], they were excluded from this study because they have a wide variety of indications.

(a) Observation periods before the PMDA alert:

Period A: December 1, 2010-May 31, 2011 (6 months)

Period B: June 1, 2011-November 30, 2011 (6 months).

(b) Observation periods after the PMDA alert:

Period C: December 1, 2011-May 31, 2012 (6 months)

Period D: June 1, 2012-November 30, 2012 (6 months).

The PMDA alert was issued in October 2011; however, the division between periods $\mathrm{B}$ and $\mathrm{C}$ was set as November 30, 2011 in consideration of the estimated time (1-2 months) required for the details of the alert to be disseminated among the relevant medical institutions.

\subsection{Clinical Outcomes}

The point estimation and $95 \%$ confidence interval (CI) for the following assessment items were calculated for periods A through D.

(a) The percentage of $\mathrm{AR}$ and NR patients tested for HBV-DNA (at any frequency), and the percentage of these patients regularly tested (at least once every 3 months) for HBV-DNA. (b) The percentage of NR patients tested for $\mathrm{HBsAg}$ before beginning immunosuppressive agent treatment, the percentage of these patients who were HBsAg negative, and the percentage of $\mathrm{HBsAg}$ negative patients tested for $\mathrm{HBcAb}$ or hepatitis $\mathrm{B}$ surface antibody (HBsAb).

\subsection{Statistical Analysis}

Patients receiving immunosuppressive agents were compared before and after the PMDA alert to check whether the rates of hepatitis B testing increased. Patients receiving immunosuppressive agents are defined as patients receiving any of the immunosuppressive agents listed in Table 3 "Appendix" at least once during each period (A-D).

On the basis of the protocol for this study (approved by the Seisenkai Matsumoto Clinic Institutional Review Board on September 19, 2014, according to Japanese ethical guidelines for epidemiologic research [9]), MDV conducted aggregate analysis of snapshot data from the clinical database on September 22, 2014. The results were supplied to the authors in Excel (Microsoft) spreadsheet and graph form.

Definitions and analysis methods for each assessment item are as follows:

Rates of HBV-DNA testing in AR and NR patients The rates and $95 \%$ CIs for HBV-DNA testing were calculated using the number of $\mathrm{AR}$ and NR patients receiving an immunosuppressive agent during each period (A-D) as the denominator and the number of patients tested for HBVDNA as the numerator. $95 \%$ CIs were estimated in all analyses using the Clopper-Pearson interval.

The rates and $95 \%$ CIs for regular HBV-DNA testing were calculated using the number of AR and NR patients receiving an immunosuppressive agent during each period (A-D) as the denominator and the number of patients tested regularly for HBV-DNA as the numerator.

Rates of HBsAg testing, HBsAg-negative patients, $H B c A b$ testing, and HBsAb testing in NR patients The rates and $95 \%$ CIs for HBsAg testing were calculated using the number of NR patients starting an immunosuppressive agent in each period (A-D) as the denominator and the number of these patients tested for $\mathrm{HBsAg}$ before immunosuppressive agent treatment (in the 60 days up to and including the start of treatment) as the numerator. The rates and $95 \%$ CIs for HBsAg-negative patients were calculated using the number of patients tested for $\mathrm{HBsAg}$ as the denominator and the number of patients who tested negative as the numerator. The rates of $\mathrm{HBcAb}$ and $\mathrm{HBsAb}$ testing in HBsAg-negative patients was calculated using the number of HBsAg-negative patients as the denominator and the number of these patients tested for $\mathrm{HBcAb}$ and $\mathrm{HBs} \mathrm{Ab}$ as the numerator. 
The following aggregate analyses were also conducted for each rate above:

Table showing patient background Summary statistics and number of cases in each category (\%) for the following parameters: sex; age; disease at start of observation; hospital scale (number of beds); and immunosuppressive agent.

Sub-group analyses Analysis by type of immunosuppressive agent (immunosuppressant, antineoplastic agent, antirheumatic drug) and disease (rheumatoid arthritis, hematological malignancies [including leukemia, lymphoma, and multiple myeloma], solid cancers, hematological malignancies and solid cancers).

Number of patients with hepatitis $B$ or identified as $H B V$ carriers Percentages of patients newly administered a hepatitis B anti-viral drug (Table 4 in "Appendix") and patients with hepatitis B or identified as HBV carriers (Table 5 in "Appendix") following a negative HBsAg test result.

\section{Results}

Aggregate analysis was conducted regarding the frequency of tests for detecting or monitoring HBV and the percentage of patients tested for hepatitis B before (periods A and B) and after (periods $C$ and D) the alert was issued (Fig. 1).

A total of 9866 patients (AR 4506; NR 5360) were extracted from the MDV clinical database and investigated (Table 1). A linear increasing trend was observed in the

Table 1 Patients' background (already and newly receiving immunosuppressive agents)

\begin{tabular}{|c|c|c|c|c|c|c|c|c|c|c|}
\hline \multirow[t]{2}{*}{ Background items } & \multicolumn{2}{|l|}{ All periods ${ }^{\mathrm{a}}$} & \multicolumn{2}{|l|}{ Period A } & \multicolumn{2}{|l|}{ Period B } & \multicolumn{2}{|l|}{ Period C } & \multicolumn{2}{|l|}{ Period D } \\
\hline & No. & $\%$ & No. & $\%$ & No. & $\%$ & No. & $\%$ & No. & $\%$ \\
\hline $\begin{array}{l}\text { No. of patients (at start of } \\
\text { observation) }\end{array}$ & 9866 & - & 5571 & - & 5710 & - & 6101 & - & 6315 & - \\
\hline \multicolumn{11}{|l|}{ Sex } \\
\hline Male & 4287 & 43.45 & 2262 & 40.60 & 2357 & 41.28 & 2537 & 41.58 & 2588 & 40.98 \\
\hline Female & 5579 & 56.55 & 3309 & 59.40 & 3353 & 58.72 & 3564 & 58.42 & 3727 & 59.02 \\
\hline Unknown & 0 & 0.00 & 0 & 0.00 & 0 & 0.00 & 0 & 0.00 & 0 & 0.00 \\
\hline \multicolumn{11}{|l|}{ Age (years) ${ }^{\mathrm{b}}$} \\
\hline$<15$ & 174 & 1.76 & 96 & 1.72 & 96 & 1.68 & 102 & 1.67 & 97 & 1.54 \\
\hline $15-64$ & 5433 & 55.07 & 3223 & 57.85 & 3280 & 57.44 & 3474 & 56.94 & 3559 & 56.36 \\
\hline $65-74$ & 2361 & 23.93 & 1299 & 23.32 & 1354 & 23.71 & 1433 & 23.49 & 1505 & 23.83 \\
\hline$\geq 75$ & 1898 & 19.24 & 953 & 17.11 & 980 & 17.16 & 1092 & 17.90 & 1154 & 18.27 \\
\hline Unknown & 0 & 0.00 & 0 & 0.00 & 0 & 0.00 & 0 & 0.00 & 0 & 0.00 \\
\hline Mean age \pm SD & $58.6 \pm 18.0$ & - & $57.6 \pm 17.9$ & - & $57.7 \pm 17.8$ & - & $57.8 \pm 18.0$ & - & $58.0 \pm 17.9$ & - \\
\hline Median age & 62 & - & 61 & - & 61 & - & 62 & - & 62 & - \\
\hline Max.-min. & $98-0$ & - & $98-0$ & - & $98-0$ & - & $97-0$ & - & $97-0$ & - \\
\hline \multicolumn{11}{|c|}{ Diseases at start of observation in each period } \\
\hline Rheumatoid arthritis & 3452 & 34.99 & 2194 & 39.38 & 2209 & 38.69 & 2405 & 39.42 & 2503 & 39.64 \\
\hline \multicolumn{11}{|l|}{ Malignant neoplasm } \\
\hline Solid cancer & 537 & 5.44 & 224 & 4.02 & 238 & 4.17 & 268 & 4.39 & 262 & 4.15 \\
\hline Hematological malignancy & 2422 & 24.55 & 1009 & 18.11 & 1044 & 18.28 & 1073 & 17.59 & 1100 & 17.42 \\
\hline $\begin{array}{l}\text { Hematological malignancy and } \\
\text { solid cancer (multiple) }\end{array}$ & 414 & 4.20 & 134 & 2.41 & 135 & 2.36 & 133 & 2.18 & 121 & 1.92 \\
\hline Other & 18 & 0.18 & 7 & 0.13 & 12 & 0.21 & 13 & 0.21 & 13 & 0.21 \\
\hline \multicolumn{11}{|l|}{ Hospital scale (no. of beds) } \\
\hline$<200$ & 1022 & 10.36 & 619 & 11.11 & 620 & 10.86 & 658 & 10.79 & 720 & 11.40 \\
\hline $200-499$ & 3684 & 37.34 & 1923 & 34.52 & 1976 & 34.61 & 2109 & 34.57 & 2187 & 34.63 \\
\hline$\geq 500$ & 5160 & 52.30 & 3029 & 54.37 & 3114 & 54.54 & 3334 & 54.65 & 3408 & 53.97 \\
\hline \multicolumn{11}{|c|}{ Immunosuppressive agents (incl. duplicate counts) } \\
\hline Antineoplastic agent & 2537 & 25.71 & 947 & 17.00 & 989 & 17.32 & 982 & 16.10 & 1000 & 15.84 \\
\hline Antirheumatic drug & 2290 & 23.21 & 1480 & 26.57 & 1545 & 27.06 & 1671 & 27.39 & 1780 & 28.19 \\
\hline Immunosuppressant & 5695 & 57.72 & 3384 & 60.74 & 3438 & 60.21 & 3759 & 61.61 & 3860 & 61.12 \\
\hline
\end{tabular}

a In the 'All periods' column, each patient is counted once, even if treated in more than one period

b Age at the start of the first administration of immunosuppressive agents in each period 
Fig. 2 a Percentage of all patients treated with immunosuppressive agents who were tested for HBV-DNA. For all patients already or newly receiving an

immunosuppressive agent, we estimated the percentage of patients tested for HBV-DNA. Mean \% [95\% CI], $n$ number of patients tested for HBV-DNA/ investigated patients in each period. b Percentage of patients in each disease type who were tested for HBV-DNA. For patients already or newly receiving an immunosuppressive agent, we estimated the percentage of patients tested for HBV-DNA in each disease type. Mean \% [95\% CI], $n$ number of patients tested for HBV-DNA/ investigated patients in each period. c Percentage of patients in each drug type who were tested for HBV-DNA. For patients already or newly receiving an

immunosuppressive agent, we estimated the percentage of patients tested for HBV-DNA in each drug type. Mean \% [95\% $\mathrm{CI}], n$ number of patients tested for HBV-DNA/investigated patients in each period

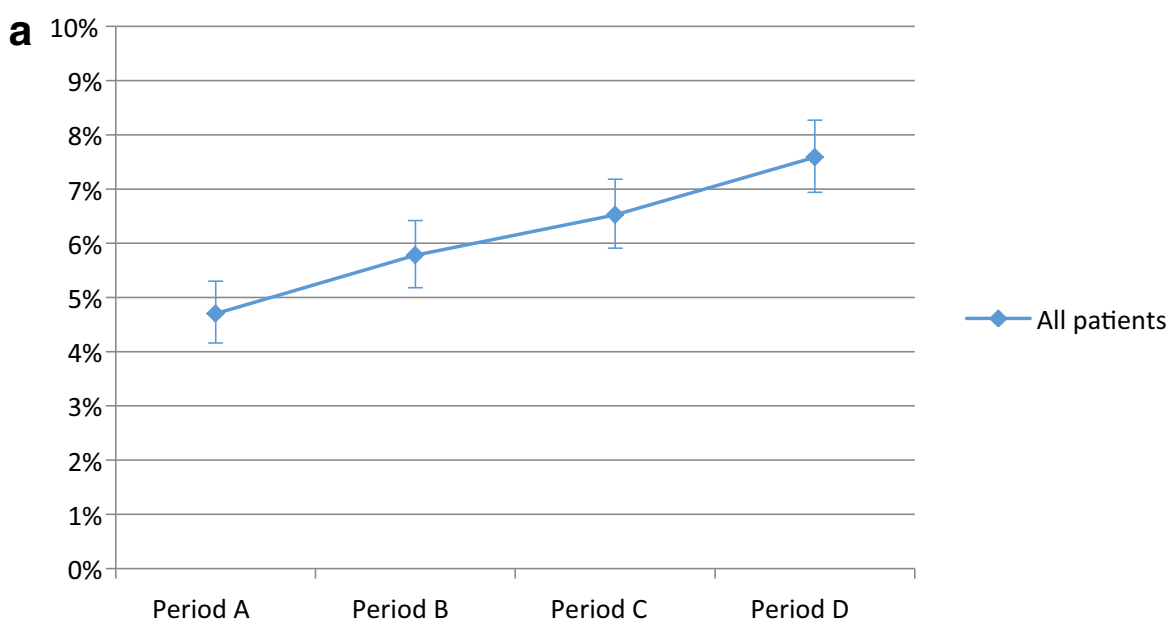

\begin{tabular}{|l|c|c|c|c|}
\hline & Period A & Period B & Period C & Period D \\
\hline All patients & $4.70[4.16-5.30]$ & $5.78[5.18-6.42]$ & $6.52[5.91-7.18]$ & $7.59[6.94-8.27]$ \\
& $\mathrm{n}=262 / 5571$ & $\mathrm{n}=330 / 5710$ & $\mathrm{n}=398 / 6101$ & $\mathrm{n}=479 / 6315$ \\
\hline
\end{tabular}

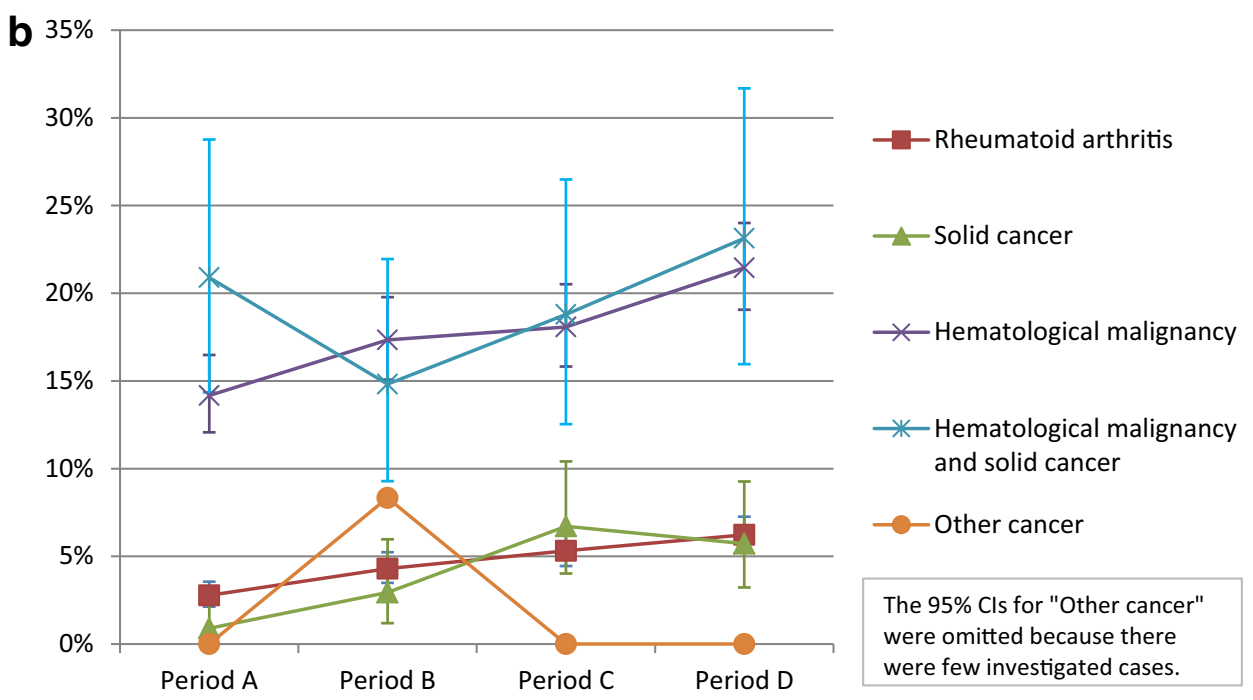

\begin{tabular}{|c|c|c|c|c|}
\hline & Period A & Period B & Period C & Period D \\
\hline $\begin{array}{l}\text { Rheumatoid } \\
\text { arthritis }\end{array}$ & $\begin{array}{c}2.78[2.13-3.56] \\
n=61 / 2194\end{array}$ & $\begin{array}{c}4.30[3.49-5.24] \\
n=95 / 2209\end{array}$ & $\begin{array}{c}5.32[4.45-6.30] \\
n=128 / 2405\end{array}$ & $\begin{array}{c}6.23[5.31-7.26] \\
n=156 / 2503\end{array}$ \\
\hline Solid cancer & $\begin{array}{c}0.89[0.10-3.19] \\
n=2 / 224\end{array}$ & $\begin{array}{c}2.94[1.19-5.97] \\
n=7 / 238\end{array}$ & $\begin{array}{c}6.72[4.02-10.41] \\
n=18 / 268\end{array}$ & $\begin{array}{c}5.73[3.23-9.27] \\
n=15 / 262\end{array}$ \\
\hline $\begin{array}{l}\text { Hematological } \\
\text { malignancy }\end{array}$ & $\begin{array}{c}14.17[12.07-16.48] \\
n=143 / 1009\end{array}$ & $\begin{array}{c}17.34[15.08-19.78] \\
n=181 / 1044\end{array}$ & $\begin{array}{c}18.08[15.82-20.52] \\
n=194 / 1073\end{array}$ & $\begin{array}{c}21.45[19.06-24.01] \\
n=236 / 1100\end{array}$ \\
\hline $\begin{array}{l}\text { Hematological } \\
\text { malignancy and } \\
\text { solid cancer }\end{array}$ & $\begin{array}{c}20.90[14.35-28.77] \\
n=28 / 134\end{array}$ & $\begin{array}{c}14.81[9.29-21.95] \\
n=20 / 135\end{array}$ & $\begin{array}{c}18.80[12.54-26.49] \\
n=25 / 133\end{array}$ & $\begin{array}{c}23.14[15.96-31.68] \\
n=28 / 121\end{array}$ \\
\hline Other cancer & $\begin{array}{c}0.00[0.00-40.97] \\
n=0 / 7\end{array}$ & $\begin{array}{c}8.33[0.21-38.48] \\
n=1 / 12\end{array}$ & $\begin{array}{c}0.00[0.00-24.71] \\
n=0 / 13\end{array}$ & $\begin{array}{c}0.00[0.00-24.71] \\
n=0 / 13\end{array}$ \\
\hline
\end{tabular}


Fig. 2 continued

Fig. 3 Percentage of all patients treated with immunosuppressive agents who were tested for HBV-DNA more than once every 3 months. For all patients already or newly receiving an immunosuppressive agent, we estimated the percentage of patients tested for HBV-DNA more than once every 3 months. Mean \% [95\% CI],

$n=$ number of patients tested for HBV-DNA more than once every 3 months/investigated patients in each period

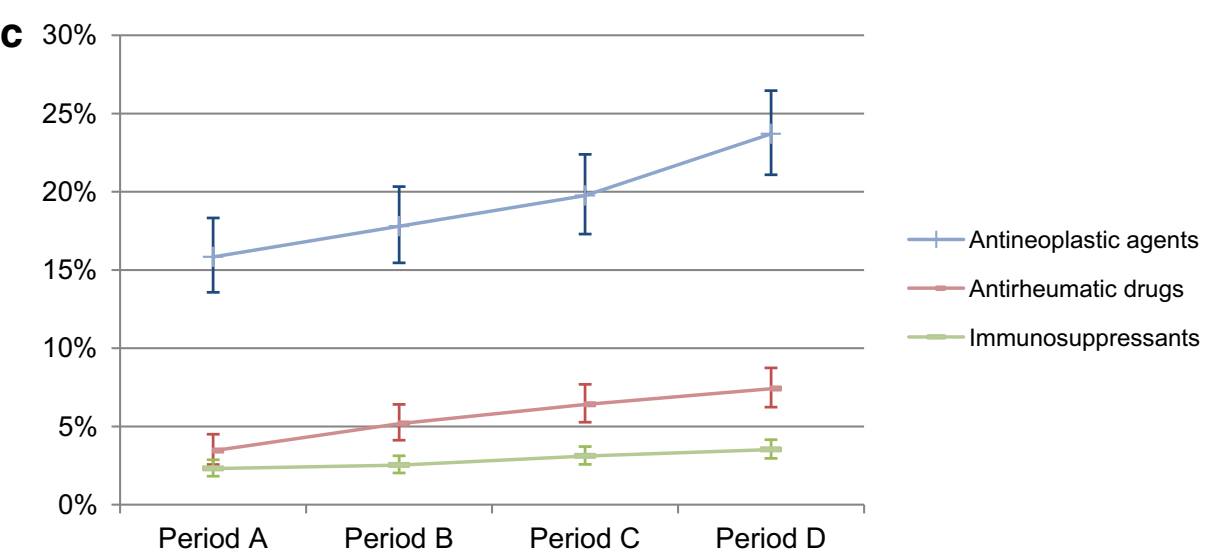

\begin{tabular}{|c|c|c|c|c|}
\hline & Period A & Period B & Period C & Period D \\
\hline Antineoplastic agents & $\begin{array}{c}15.84 \quad[13.57-18.33] \\
n=150 / 947\end{array}$ & $\begin{array}{c}17.80[15.46-20.33] \\
n=176 / 989\end{array}$ & $\begin{array}{c}19.76[17.30-22.39] \\
n=194 / 982\end{array}$ & $\begin{array}{c}23.70[21.09-26.47] \\
n=237 / 1000\end{array}$ \\
\hline Antirheumatic drugs & $\begin{array}{c}3.45[2.57-4.51] \\
n=51 / 1480\end{array}$ & $\begin{array}{c}5.18[4.12-6.41] \\
n=80 / 1545\end{array}$ & $\begin{array}{c}6.40[5.27-7.69] \\
n=107 / 1671\end{array}$ & $\begin{array}{c}7.42[6.24-8.74] \\
n=132 / 1780\end{array}$ \\
\hline Immunosuppressants & $\begin{array}{c}2.30[1.82-2.87] \\
n=78 / 3384\end{array}$ & $\begin{array}{c}2.53[2.03-3.12] \\
n=87 / 3438\end{array}$ & $\begin{array}{c}3.11[2.58-3.72] \\
n=117 / 3759\end{array}$ & $\begin{array}{c}3.52[2.96-4.16] \\
n=136 / 3860\end{array}$ \\
\hline
\end{tabular}

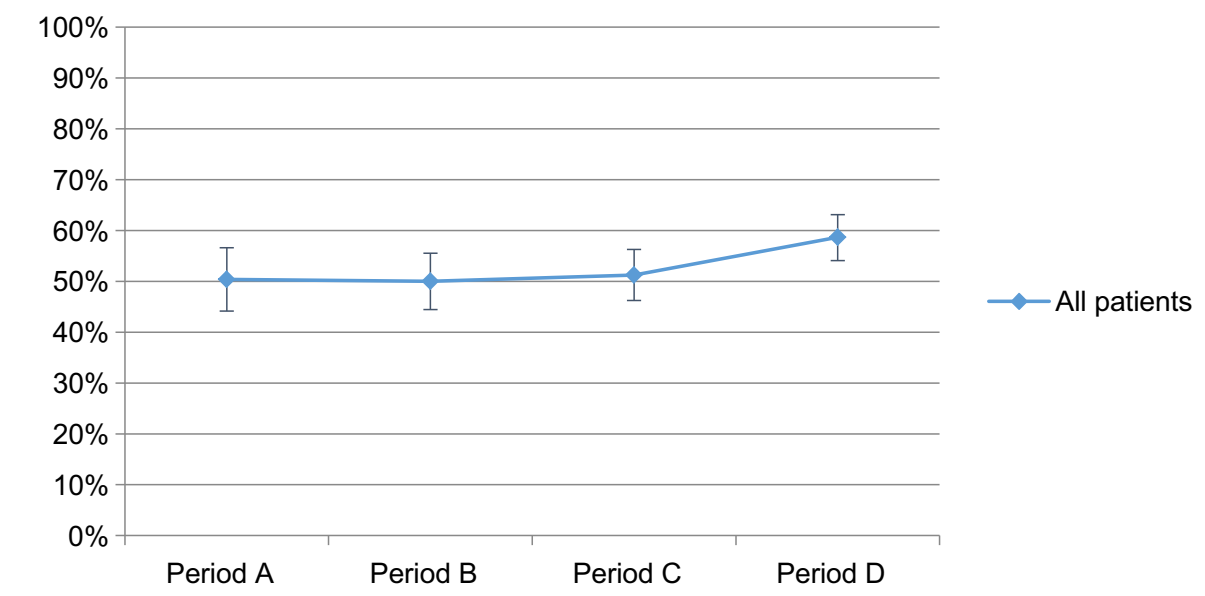

\begin{tabular}{|l|c|c|c|c|}
\hline & Period A & Period B & Period C & Period D \\
\hline All & $50.38[44.16-56.60]$ & $50.00[44.47-55.53]$ & $51.26[46.22-56.27]$ & $58.66[54.10-63.12]$ \\
patients & $\mathrm{n}=132 / 262$ & $\mathrm{n}=165 / 330$ & $\mathrm{n}=204 / 398$ & $\mathrm{n}=281 / 479$ \\
\hline
\end{tabular}

rates of HBV-DNA testing in AR and NR patients (Period A: $4.70 \%$ [95 \% CI 4.16-5.30]; Period B: $5.78 \%$ [5.18-6.42]; Period C: $6.52 \%$ [5.91-7.18]; and Period D: $7.59 \%$ [6.94-8.27]). No changes in the rates of regular HBV-DNA testing were observed for periods A through C; however, an increasing trend was observed between periods C and D (Period A: $50.38 \%$ [95 \% CI 44.16-56.60]; Period B: $50.00 \%$ [44.47-55.53]; Period C: $51.26 \%$ [46.22-56.27]; and Period D: $58.66 \%$ [54.10-63.12]).
Thus, both rates showed an increasing trend after the alert was issued (Figs 2a, 3).

Conversely, no post-alert changes were seen in the rates of HBsAg testing before beginning immunosuppressive agent treatment in the 5360 NR patients (Table 2) (Period A: $48.72 \%$ [95\% CI 45.99-51.45]; Period B: $50.45 \%$ [47.73-53.17]; Period C: $49.39 \%$ [46.72-52.06]; and Period D: $51.34 \%$ [48.59-54.09]; Fig. 4); in the rates of negative results on HBsAg testing (excluding unclear 
Table 2 Patient background (newly receiving immunosuppressive agents)

\begin{tabular}{|c|c|c|c|c|c|c|c|c|c|c|}
\hline \multirow[t]{2}{*}{ Background items } & \multicolumn{2}{|l|}{ All periods } & \multicolumn{2}{|l|}{ Period A } & \multicolumn{2}{|l|}{ Period B } & \multicolumn{2}{|l|}{ Period C } & \multicolumn{2}{|l|}{ Period D } \\
\hline & No. & $\%$ & No. & $\%$ & No. & $\%$ & No. & $\%$ & No. & $\%$ \\
\hline $\begin{array}{l}\text { No. of patients (at start of } \\
\text { observation) }\end{array}$ & 5360 & - & 1328 & - & 1338 & - & 1391 & - & 1303 & - \\
\hline \multicolumn{11}{|l|}{ Sex } \\
\hline Male & 2557 & 47.71 & 644 & 48.49 & 661 & 49.40 & 653 & 46.94 & 599 & 45.97 \\
\hline Female & 2803 & 52.29 & 684 & 51.51 & 677 & 50.60 & 738 & 53.06 & 704 & 54.03 \\
\hline Unknown & 0 & 0.00 & 0 & 0.00 & 0 & 0.00 & 0 & 0.00 & 0 & 0.00 \\
\hline \multicolumn{11}{|l|}{ Age $(\text { years })^{\mathrm{a}}$} \\
\hline$<15$ & 103 & 1.92 & 28 & 2.11 & 23 & 1.72 & 30 & 2.16 & 22 & 1.69 \\
\hline $15-64$ & 2787 & 52.00 & 710 & 53.46 & 714 & 53.36 & 699 & 50.25 & 664 & 50.96 \\
\hline $65-74$ & 1315 & 24.53 & 320 & 24.10 & 329 & 24.59 & 338 & 24.30 & 328 & 25.17 \\
\hline$\geq 75$ & 1155 & 21.55 & 270 & 20.33 & 272 & 20.33 & 324 & 23.29 & 289 & 22.18 \\
\hline Unknown & 0 & 0.00 & 0 & 0.00 & 0 & 0.00 & 0 & 0.00 & 0 & 0.00 \\
\hline Mean \pm SD & $59.7 \pm 18.3$ & - & $59.4 \pm 18.4$ & - & $59.3 \pm 18.2$ & - & $60.1 \pm 18.5$ & - & $59.9 \pm 18.2$ & - \\
\hline Median & 63 & - & 63 & - & 63 & - & 64 & - & 63 & - \\
\hline Max.-min. & $98-0$ & - & $98-0$ & - & $98-0$ & - & $97-0$ & - & $95-0$ & - \\
\hline \multicolumn{11}{|c|}{ Diseases (at the start of observation in each period) } \\
\hline Rheumatoid arthritis & 1434 & 26.75 & 324 & 24.40 & 343 & 25.64 & 391 & 28.11 & 329 & 25.25 \\
\hline \multicolumn{11}{|l|}{ Malignant neoplasm } \\
\hline Solid cancer & 312 & 5.82 & 59 & 4.44 & 70 & 5.23 & 80 & 5.75 & 66 & 5.07 \\
\hline Hematological malignancy & 1783 & 33.26 & 456 & 34.34 & 461 & 34.45 & 448 & 32.21 & 442 & 33.92 \\
\hline $\begin{array}{l}\text { Hematological malignancy and } \\
\text { solid cancer (multiple) }\end{array}$ & 307 & 5.73 & 68 & 5.12 & 75 & 5.61 & 57 & 4.10 & 58 & 4.45 \\
\hline Others & 11 & 0.21 & 3 & 0.23 & 2 & 0.15 & 2 & 0.14 & 2 & 0.15 \\
\hline \multicolumn{11}{|l|}{ Hospital scale (no. of beds) } \\
\hline$<200$ & 444 & 8.28 & 94 & 7.08 & 93 & 6.95 & 122 & 8.77 & 135 & 10.36 \\
\hline $200-499$ & 2295 & 42.82 & 619 & 46.61 & 545 & 40.73 & 582 & 41.84 & 549 & 42.13 \\
\hline$\geq 500$ & 2621 & 48.90 & 615 & 46.31 & 700 & 52.32 & 687 & 49.39 & 619 & 47.51 \\
\hline \multicolumn{11}{|c|}{ Immunosuppressive agents (incl. duplicate counts) } \\
\hline Antineoplastic agent & 1981 & 36.96 & 497 & 37.42 & 514 & 38.42 & 471 & 33.86 & 487 & 37.38 \\
\hline Antirheumatic drug & 896 & 16.72 & 210 & 15.81 & 210 & 15.70 & 207 & 14.88 & 210 & 16.12 \\
\hline Immunosuppressant & 2788 & 52.01 & 655 & 49.32 & 654 & 48.88 & 772 & 55.50 & 652 & 50.04 \\
\hline
\end{tabular}

${ }^{a}$ Age at the start of the first administration of immunosuppressive agents in each period

results) (Period A: $97.60 \%$ [95 \% CI 93.80-99.42]; Period B: $\quad 98.90 \%$ [95.82-99.93]; Period C: $97.40 \%$ [93.48-99.29]; and Period D: 98.15\% [94.46-99.70]; Fig. 4); or the rates of $\mathrm{HBcAb}$ and $\mathrm{HBsAb}$ testing in HBsAg-negative patients (Period A: $73.62 \%$ [95\% CI 66.15-80.21]; Period B: $74.86 \%$ [67.84-81.04]; Period C: $67.33 \% \quad[59.20-74.76] ;$ and Period D: $74.84 \%$ [67.35-81.39]; Fig. 5).

By disease type, mean rates of HBV-DNA testing were comparatively high for patients with hematological malignancies or hematological malignancies and solid cancers (multiple cancers) (14-23\%) and low for those with solid cancers or rheumatoid arthritis (1-7\%), excluding other cancer groups because of a limited number of investigated patients; however, for all disease types, rates of testing showed an increasing trend after the alert was issued (Fig. 2b). By drug type, mean rates of HBVDNA testing were high for patients receiving antineoplastic agents (16-24\%) and low for those receiving antirheumatic drugs (3-7\%) or immunosuppressants (2-4\%); however, for all drug types, an increasing trend was again observed after the alert was issued (Fig. 2c).

The rates of regular HBV-DNA testing in AR and NR patients and for HBsAg, $\mathrm{HBcAb}$, and HBsAb testing in NR patients showed no changes on subgroup analyses. However, similar differences in the rates of testing depending on the disease or drug type were observed for these tests and for HBV-DNA testing.

Because only four of the $9866 \mathrm{AR}$ and NR patients were newly administered hepatitis $\mathrm{B}$ anti-viral drugs and shown to have HBV infection or be HBV carriers, no further analysis of this subgroup was conducted. 
Fig. 4 Percentage of all patients newly receiving an immunosuppressive agent who were tested for HBs antigen. For all patients newly receiving an immunosuppressive agent, we estimated the percentage of patients tested for hepatitis B surface (HBs) antigen. Mean $\%$ [95\% CI], $n=$ number of patients tested for HBs antigen/ investigated patients in each period

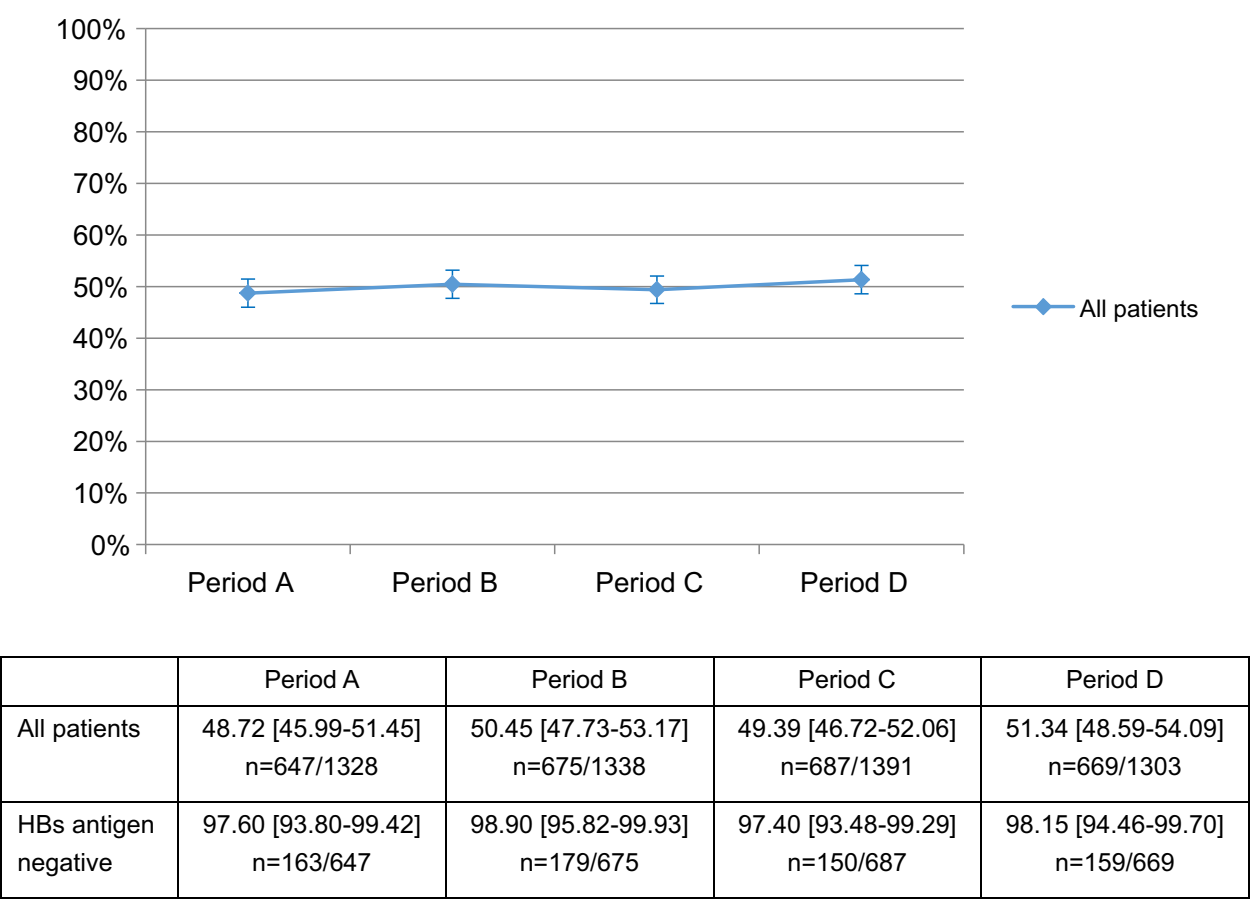

Fig. 5 Percentage of hepatitis B surface (HBs) antigennegative patients newly receiving an immunosuppressive agent who were tested for hepatitis B core (HBc) and/or HBs antibody. For all HBs antigen-negative patients newly receiving an immunosuppressive agent, we estimated the percentage of patients tested for $\mathrm{HBc}$ and/or HBs antibody. Mean \% [95 \% $\mathrm{CI}], n=$ number of patients tested for HBc and/or HBs antibody/investigated patients who were $\mathrm{HBs}$ antigen-negative in each period

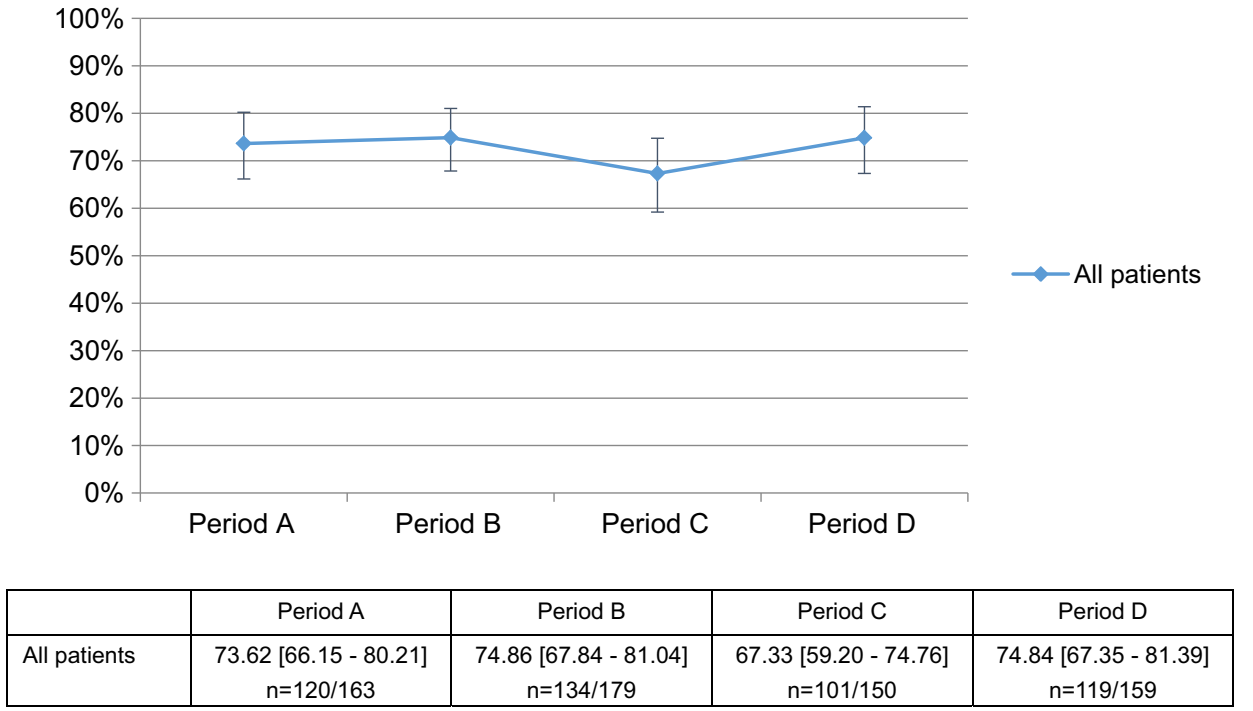

\section{Discussion}

Rates of HBV-DNA testing showed an increasing trend after the PMDA alert was issued. However, it is difficult to attribute these changes directly to the alert. Although the October 2011 PMDA alert concerned all immunosuppressive agents, many pharmaceutical companies had already individually issued alerts for these agents, with the package inserts already stating or being revised to include wording such as "development of hepatitis caused by reactivation of hepatitis
B virus". In particular, package insert revisions implemented in March 2011, 7 months before the PMDA alert, may have affected our findings. While this study compared testing behavior before and after a PMDA alert, observation periods in future database studies should consider the status of manufacturer-issued alerts for each individual drug.

No post-alert changes were observed in the rates of $\mathrm{HBsAg}$ testing; rates of negative $\mathrm{HBsAg}$ test results (excluding unclear results); or rates of $\mathrm{HBcAb}$ and $\mathrm{HBsAb}$ testing in $\mathrm{HBsAg}$ negative patients before beginning immunosuppressive agent 
treatment. One explanation for why the rate of monitoring tests such as HBV-DNA might have increased while the rate of screening tests including $\mathrm{HBs} \mathrm{Ag}, \mathrm{HBcAb}$, and $\mathrm{HBsAb}$ remained unchanged is that the PMDA alert was for hepatitis $B$ virus growth in hepatitis B virus carriers using drugs with immunosuppressive effects, and it recommended monitoring tests including the HBV-DNA test. Screening tests were not specifically recommended.

The different rates of HBV-DNA testing for different disease types observed in subgroup analysis may be due to disease-related differences in the percentage of patients requiring HBV-DNA monitoring. These findings suggest that clinical databases can be used to identify overall testing rates and differences in testing rates by disease and drug type.

Although no clear behavioral changes were identified after the alert, the gradual overall increase in the rates of HBV-DNA testing suggests the occurrence of changes unrelated to the alert. Future studies should take into consideration the apparent differences in testing rates for different diseases and drug types as well as the changes in testing behavior observed across all four periods, from before to after the alert.

Although these findings may have been affected by the characteristics of the clinical database used in the study, they indicate the potential for secondary application of clinical databases to verify the impact of risk minimization activities. Using a different clinical database to investigate the reproducibility of these findings would demonstrate their robustness and confirm the utility of clinical databases for such verification.

\subsection{Limitations}

Several limitations to this study should be noted. Because the data source was limited to acute care hospitals, the findings cannot be generalized. Furthermore, difficulty confirming the status of patients transferred to and from hospitals other than data-source institutions limits the accuracy of assessment of patient follow-up and previous treatment.

A wide range of immunosuppressive agents were investigated, increasing the likelihood of confounding factors such as the primary disease for which the drug was prescribed, the indication of the drug, the hospital department, and whether the treatment was inpatient or outpatient. Appropriate adjustment for these confounding factors is an issue for continuing investigation.

It may be premature to definitively state that clinical databases are useful for verifying the impact of risk minimization activities solely on the basis of the linear increasing trend in rates of HBV-DNA testing observed in this study. Repeatability should therefore be confirmed using multiple databases.

\section{Conclusion}

HBV-DNA testing is important for ensuring rapid treatment and preventing exacerbation in cases of new and reactivated hepatitis B. The rates of HBV-DNA testing showed an increasing trend after the PMDA alert regarding the risk of hepatitis $B$ reactivation with immunosuppressive agents. No changes were observed in the rates of $\mathrm{HBsAg}, \mathrm{HBcAb}$, and $\mathrm{HBs} A b$ testing. The PMDA alert appears to have been effective at recommending monitoring tests including the HBV-DNA test but ineffective for the screening tests. Therefore, the ability to estimate testing rates using the clinical database suggests that this secondary application of clinical databases may be effective for verifying the impact of risk minimization activities.

Acknowledgments We thank Daisuke Matsubayashi (MDV), who manages the clinical database used in this study and who performed and supplied the results of the aggregate analysis based on our study protocol.

\section{Compliance with Ethical Standards}

Funding This research received no specific grant from any funding agency in the public, commercial or not-for-profit sectors.

Conflict of interest Yukio Udagawa, Shinya Ohno, Shintaro Nakagawa, Kazutaka Sugimoto and Joji Mochizuki are employees of Chugai Pharmaceutical Co., Ltd., which markets two of the immunosuppressive agents (mycophenolate mofetil and rituximab) investigated in this study. To account for potential conflicts of interest, individual drugs were not directly compared in this study. The authors had no direct access to primary data, which were analyzed by Medical Data Vision Co, Ltd according to the study protocol.

Ethical approval This study is registered with the Japanese Ministry of Health, Labour and Welfare's research ethics committee reporting system (No. 11001028) and UMIN Clinical Trials Registry (No. UMIN000015628).

Open Access This article is distributed under the terms of the Creative Commons Attribution-NonCommercial 4.0 International License (http://creativecommons.org/licenses/by-nc/4.0/), which permits any noncommercial use, distribution, and reproduction in any medium, provided you give appropriate credit to the original author(s) and the source, provide a link to the Creative Commons license, and indicate if changes were made.

\section{Appendix}

See Tables 3, 4 and 5.

Table 3 Immunosuppressive agents

\begin{tabular}{lll}
\hline & Nonproprietary name & ATC code \\
\hline Immunosuppressants & Azathioprine & L04X0 \\
& Everolimus & L04X0 \\
& Gusperimus & L04X0 \\
\hline
\end{tabular}


Table 3 continued

\begin{tabular}{lll}
\hline & Nonproprietary name & ATC code \\
\hline & Thymoglobulin & L04X0 \\
& Ciclosporin & L04X0 \\
Tacrolimus & L04X0 \\
Basiliximab & L04X0 \\
Mycophenolate mofetil & L04X0 \\
& Mizoribine & L04X0 \\
& Muromonab-CD3 & - \\
Antineoplastic agents & Everolimus & L01H0 \\
& Fludarabine & L01B0 \\
& Rituximab & L01G0 \\
Antirheumatic agents & Adalimumab & L04B0 \\
& Abatacept & M01C0 \\
& Infliximab & L04B0 \\
& Etanercept & L04B0 \\
& Golimumab & L04B0 \\
\hline
\end{tabular}

Methotrexate and steroids were excluded from this study because of their wide range of indications

Drugs were defined according to anatomical therapeutic chemical (ATC) classifications

Table 4 Antiviral agents for the treatment of HBV infection

\begin{tabular}{ll}
\hline Nonproprietary name & ATC code \\
\hline Adefovir pivoxil & J05B1 \\
Entecavir & J05B1 \\
Lamivudine & J05B1, J05C1 \\
Interferon alfa (BALL-1) & J03B1 \\
Interferon alfa (NAMALWA) & J03B1 \\
Interferon alfa 2b & J03B1 \\
Interferon beta & J03B2
\end{tabular}

Drugs were defined according to anatomical therapeutic chemical (ATC) classifications

Table 5 Patients diagnosed with hepatitis B or carrying hepatitis B virus

\begin{tabular}{|c|c|c|c|}
\hline $\begin{array}{l}\text { ICD10 } \\
\text { code }\end{array}$ & ICD10 name & $\begin{array}{l}\text { Disease } \\
\text { code }\end{array}$ & $\begin{array}{l}\text { Reported disease } \\
\text { name }\end{array}$ \\
\hline B16.2 & $\begin{array}{l}\text { Acute hepatitis B } \\
\text { without delta-agent } \\
\text { with hepatic coma }\end{array}$ & 8842151 & $\begin{array}{l}\text { Acute hepatitis B } \\
\text { with hepatic coma }\end{array}$ \\
\hline B16.9 & $\begin{array}{l}\text { Acute hepatitis B } \\
\text { without delta-agent } \\
\text { and without hepatic } \\
\text { coma }\end{array}$ & 8830087 & $\begin{array}{l}\text { Hepatitis B virus } \\
\text { nephropathy }\end{array}$ \\
\hline B16.9 & $\begin{array}{l}\text { Acute hepatitis B } \\
\text { without delta-agent } \\
\text { and without hepatic } \\
\text { coma }\end{array}$ & 0703002 & Hepatitis B \\
\hline
\end{tabular}

Table 5 continued

\begin{tabular}{|c|c|c|c|}
\hline $\begin{array}{l}\text { ICD10 } \\
\text { code }\end{array}$ & ICD10 name & $\begin{array}{l}\text { Disease } \\
\text { code }\end{array}$ & $\begin{array}{l}\text { Reported disease } \\
\text { name }\end{array}$ \\
\hline B16.9 & $\begin{array}{l}\text { Acute hepatitis B } \\
\text { without delta-agent } \\
\text { and without hepatic } \\
\text { coma }\end{array}$ & 8830062 & $\begin{array}{l}\text { Hepatitis B virus } \\
\text { infection }\end{array}$ \\
\hline P00.2 & $\begin{array}{l}\text { Fetus and newborn } \\
\text { affected by maternal } \\
\text { infectious and } \\
\text { parasitic diseases }\end{array}$ & 8843998 & $\begin{array}{l}\text { Newborn affected by } \\
\text { maternal hepatitis } \\
\text { B virus infection }\end{array}$ \\
\hline B18.1 & $\begin{array}{l}\text { Chronic viral hepatitis } \\
\text { B without delta-agent }\end{array}$ & 8843999 & Type B cirrhosis \\
\hline B16.9 & $\begin{array}{l}\text { Acute hepatitis B } \\
\text { without delta-agent } \\
\text { and without hepatic } \\
\text { coma }\end{array}$ & 0703021 & Acute hepatitis B \\
\hline B16.9 & $\begin{array}{l}\text { Acute hepatitis B } \\
\text { without delta-agent } \\
\text { and without hepatic } \\
\text { coma }\end{array}$ & 8830063 & Fulminant hepatitis B \\
\hline B18.1 & $\begin{array}{l}\text { Chronic viral hepatitis } \\
\text { B without delta-agent }\end{array}$ & 0703003 & Chronic hepatitis B \\
\hline $\mathrm{R} 76.8$ & $\begin{array}{l}\text { Other specified } \\
\text { abnormal } \\
\text { immunological } \\
\text { findings in serum }\end{array}$ & 8830086 & $\begin{array}{l}\text { HBs antigen test } \\
\text { positive }\end{array}$ \\
\hline $\mathrm{Z} 22.5$ & Carrier of viral hepatitis & 8830088 & HB carrier \\
\hline R76.8 & $\begin{array}{l}\text { Other specified } \\
\text { abnormal } \\
\text { immunological } \\
\text { findings in serum }\end{array}$ & 8830085 & $\begin{array}{l}\text { HBe antigen test } \\
\text { positive }\end{array}$ \\
\hline
\end{tabular}

Diagnosis was based on the disease codes of the Medical Information System Development Center

\section{References}

1. Hanson RL, Gannon MJ, Khamo N, Sodhi M, Orr AM, Stubbings J. Improvement in safety monitoring of biologic response modifiers after the implementation of clinical care guidelines by a specialty pharmacy service in an academic health system. J Manag Care Pharm. 2013;19(1):49-67.

2. Hwang JP, Fisch MJ, Lok AS, Zhang H, Vierling JM, SuarezAlmazor ME. Trends in hepatitis B virus screening at the onset of chemotherapy in a large US cancer center. BMC Cancer. 2013;13:534-44.

3. Ikeda M, Ohshima H, Yamamto H. Present status of screening for hepatitis B virus infection in patients undergoing chemotherapy in Japan. Ann Oncol. 2013;24(Suppl. 9):ix74.

4. Prieto L, Spooner A, Hidalgo-Simon A, Rubino A, Kurz X, Arlett P. Evaluation of the effectiveness of risk minimization measures. Pharmacoepidemiol Drug Saf. 2012;21:896-9.

5. Pharmaceuticals and Medical Devices Agency, Japan. Alert for Proper Use of Drugs No. 3: hepatitis B viral growth associated with the use of drugs with immunosuppressive effects. 2011. http:// ss.pmda.go.jp/ja_all/muv_ajax.x?u=http $\% 3 \mathrm{~A} \% 2 \mathrm{~F} \% 2 \mathrm{Fwww} . p m d a$. go.jp\%2Ffiles\%2F000153777.pdf\%23page\%3D1\&p=1\&t=\&q= hepatitis +B + growth\&s=wJJncMIgUrbUQxlNl-WTXLGFP8-ys 6bvg7NuHc2tgiCVn46jaQS2SMJ-EymErL0oQJsOW12ziEvpn XExTXd18D1yUj2WkmB6xPOM-ZhKEg2dC5aifVR8p6h0e6 
0bA-QwWZE6HOURNBKX6UU5T7f-_zYmocMaqElVrl-t2rH jC_o.\&lang=jp. Accessed 17 June 2015.

6. Tsubouchi H, Kumada H, Kiyosawa K, Mochida S, Sakaida I, Tanaka E, et al. Prevention of immunosuppressive therapy or chemotherapy-induced reactivation of hepatitis B virus infection. Joint report of the intractable liver diseases study group of Japan and the Japanese study group of the standard antiviral therapy for viral hepatitis. Kanzo (Jpn J Hepatol). 2009;50:38-42.

7. Asahina Y, Hayashi N, Hiramatsu N, Izumi N, Koike K, Kumada $\mathrm{H}$, et al. Drafting Committee for Hepatitis Management Guidelines and the Japan Society of Hepatology. JSH Guidelines for the management of hepatitis B virus infection. Hepatol Res. 2014;44(Suppl. 1):1-58.

8. Japanese Society for Pharmacoepidemiology. The results of a survey of databases applicable to clinical epidemiology and pharmacoepidemiology in Japan. 2014. http://www.jspe.jp/mtstatic/FileUpload/files/JSPE_DB_TF_E.pdf. Accessed 15 June 2015.

9. The Ministry of Health, Labour and Welfare, Ministry of Education, Culture, Sports, Science and Technology (2002): Ethical guidelines for epidemiologic research. 2002. http://www.niph.go.jp/wadai/ ekigakurinri/guidelines.pdf. Accessed 13 Feb 2015. 